\title{
Delincuencia y opinión pública ${ }^{1}$
}

\author{
Instituto Universitario de Opinión Pública
}

\begin{abstract}
Resumen
Ester artículo presenta los resultados de una encuesta sobre delincuencia realizada por el IUDOP en el mes de julio, con el fin de recoger las opiniones de los salvadoreños sobre el problema de la delincuencia y recolectar las experiencias de victimización a causa de esa problemática. Los resultados muestran que la delincuencia continúa afectando a amplios sectores de la población aunque no en la misma proporción que en el pasado, además revelan que la mayoría de la población está muy preocupada por el problema y que en respuesta al sentimiento de inseguridad y a la percepción de la falta de soluciones, buena parte de los salvadoreños estarían dispuestos a apoyar acciones drásticas ilegales.
\end{abstract}

\section{Introducción}

En febrero de 1993, sólo un aĩo después de la firma de los acuerdos de paz, una encuesta exploratoria y pionera del Instituto de Opinión Pública realizada en las zonas urbanas a nivel nacional demostró que el problema de la delincuencia en ese entonces era ya un problema serio. Más del 30 por ciento de los hogares salvadoreños reportaron haber sido víctimas de la delincuencia (ver IUDOP, 1993). En ese entonces no mucha gente prestaba atención al fenómeno, aunque ya un porcentaje de la población comenzaba a mencionarlo como un problema fundamental en el país. Las respuestas discursivas más comunes de las autoridades y de algunos sectores de la sociedad -incluyendo los intelectuales - eran esencialmente dos. Por un lado se argumentaba que en el país siempre había existido delincuencia y que la creciente preocupación por la misma se debía a que, con el fín de la guerra, ya había espacio para que los salvadoreños le pusieran atención al problema de la criminalidad. Por el otro, y este argumento era más esgrimido por el lado gubernamental, se decía que después de un conflicto bélico era normal que apare-

1. Este artículo se funda en una investigación de opinión pública financiada por la Misión de la Iglesia Sueca, en el marco del Proyecto de cooperación y soporte institucional con la Universidad Centroamericana "José Simeón Cañas". 


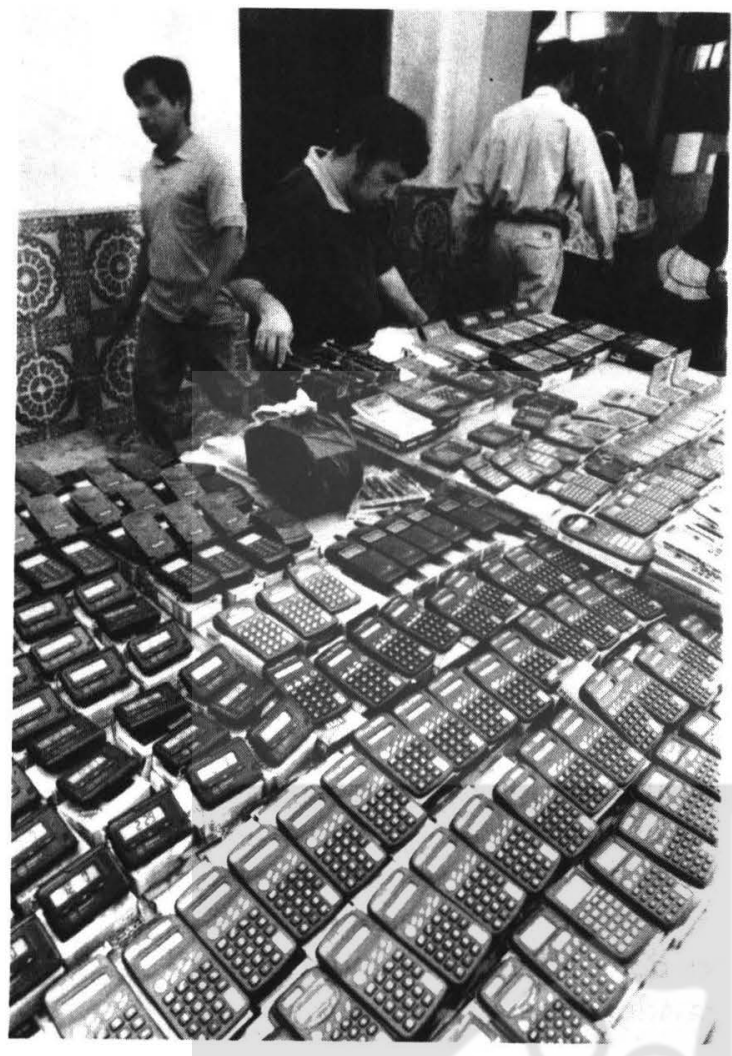

cieran problemas de delincuencia, por lo que pasado algún tiempo y a medida que la sociedad se acomodara a las nuevas condiciones de paz, el problema habría de ceder.

Al cabo de más de seis años después del tratado de paz, el fenómeno sigue presente en la vida colidiana de los salvadoreños y el concepto de la criminalidad como un problema grave del país se ha instalado definitivamente en la opinión pública. Ahora, después de enfrentar evidencias que indican una magnitud sin precedentes del problema, muy poca gente sostiene los argumentos de hace seis años, y más bien los ciudadanos piensan que el fenómeno sigue en aumento y que no tiene solución a corto plazo. Este tipo de pensamientos usualmente es fruto de la generalización de algunas experiencias cotidianas y del sentido común, pero muy rara vez es producto de investigaciones sistemáticas sobre el fenómeno y sus consecuencias. Por ello, el IUDOP ha considerado fundamental continuar con el esfuerzo de recoger los aspectos y expresiones relacionados con el problema y auscultar la opinión pública sobre el mismo, como una forma de aproximarse científicamente a la problemática. Es este contexto de necesidades y preocupaciones el que motiva esta nueva pesquisa de opinión pública sobre delincuencia

La encuesta fue realizada entre el 4 y el 12 de julio de 1998 a nivel nacional y explora las opiniones de los salvadoreños sobre la problemática de la criminalidad, tanto en lo que se refiere a sus causas, como a sus expresiones y posibles soluciones; además, dedica espacio a recolectar las opiniones sobre el trabajo de las autoridades, especialmente de la Policía Nacional Civil (PNC); y, sobre todo, se concentra en recoger las experiencias de victimización de los salvadoreños por causa de la delincuencia común y violenta. El sondeo estaba dirigido a individuos en sus hogares o centros de vivienda, no estaba dirigido a instituciones o empresas, por tanto refleja la manera en que el fenómeno afecta al ciudadano promedio, nada más.

El presente artículo se basa en ese sondeo y pretende tres cosas. En primer lugar, presenta algunos de los resultados de la encuesta, especialmente los que se refieren a la victimización por delincuencia común y violenta, a las valoraciones sobre las instituciones y a las opiniones sobre la delincuencia. En segundo lugar, quiere documentar el hecho de que las encuestas no están mostrando un aumento cuantitativo en los casos de delincuencia que afectan al ciudadano promedio. $\mathrm{Fi}$ nalmente y de manera más reflexiva, busca mostrar cómo la extrema preocupación por el fenómeno de la delincuencia está llevando a muchos ciudadanos a pedir medidas drásticas que exceden la legalidad y el respeto de los derechos de los demás.

Los datos y las ideas presentadas en este artículo no pretenden ser concluyentes, pero sí esperan contribuir decididamente a la discusión sobre la magnitud real del problema de la delincuencia común y violenta, sobre todo desde el contexto temporal; y buscan ser una llamada de alerta sobre la necesidad de buscar soluciones racionales y responsables al problema de la violencia delincuencial.

\section{La metodología de la encuesta}

\subsection{Muestra y procedimiento de selección}

La muestra de la investigación realizada por el IUDOP se diseñó de tal manera que reflejase lo más fielmente posible la totalidad de la población salvadoreña tanto a nivel nacional como a nivel 
metropolitano; ello se hizo siguiendo la misma metodología de muestreo utilizada en pesquisas anteriores sobre el tema de delincuencia, esto para hacer comparables los dalos con los datos pasados. Como es usual en las encuestas del Instituto, la muestra se construyó en función de los datos ofrecidos por el Censo Nacional de Población de 1992 y del último informe disponible de la Encuesta de Hogares de Propósitos Múltiples de la Dirección de Información del Ministerio de Economía correspondiente al año de 1996 (ver Dirección de Información, 1997). La cuota muestral incluyó 38 municipios de los catorce departamentos de la república. En cada departamento, la muestra se dividió en dos grandes sectores: urbano y rural. El primero fue dividido en cinco estratos: alto, medio-alto, medio-bajo, obrero y marginal. La cuota rural se dejó como una categoría independiente por las dificultades de encontrar criterios de tipificación en cl campo. En el muestreo se consideraron también las cuotas para los rangos de edad y para el género de los encuestados.
La aplicación del cuestionario se hizo por aproximación no sistemática a los hogares ubicados en los municipios y las zonas definidas aleatoriamente. Los entrevistadores explicaban a las personas abordadas los objetivos y el tema de la encuesta. En cada caso se entrevistó únicamente a personas que quisieran contestar (una persona por hogar) y que cumpliera con los requerimientos descritos en la boleta para completar la cuota muestral según zona, estrato social, sexo y edad.

La muestra final obtenida fue de 1,228 encuestas válidas, con un margen de error estimado de +1 - 0.04 (cuatro por ciento). El 48.4 por ciento de los encuestados pertenece al sexo masculino, mientras que el 51.6 por ciento corresponde al sexo femenino. La edad promedio es de 36.8 años con una desviación estándar de 14.1 años. Los encuestados tienen un promedio general de 7.6 años de estudio, y el 53.9 por ciento se encuentra empleado en la actualidad o posee un trabajo propio. En el Cuadro I se exhibe la distribución de la población encuestada según departamento y estrato social.

\section{Cuadro 1}

Distribución de la población encuestada según departamento y sector social

\begin{tabular}{|c|c|c|c|c|c|c|c|c|}
\hline \multirow[b]{2}{*}{ Departamento } & \multirow[b]{2}{*}{ Alto } & \multirow[b]{2}{*}{ Medio-alto } & \multicolumn{2}{|c|}{ Sector social } & \multirow[b]{2}{*}{ Marginal } & \multirow[b]{2}{*}{ Rural } & \multicolumn{2}{|c|}{ Todos } \\
\hline & & & Medio-bajo & Obrero & & & $\mathrm{N}$ & $\%$ \\
\hline Todoss & $\begin{array}{r}73 \\
5.9\end{array}$ & $\begin{array}{r}163 \\
13.3\end{array}$ & $\begin{array}{r}173 \\
14.1\end{array}$ & $\begin{array}{r}249 \\
20.3\end{array}$ & $\begin{array}{r}162 \\
13.2\end{array}$ & $\begin{array}{l}408 \\
33.2\end{array}$ & $\begin{array}{r}1228 \\
-\end{array}$ & $\overline{100.0}$ \\
\hline Ahuachapán & 3 & 4 & 4 & 7 & 4 & 40 & 62 & 5.0 \\
\hline Santa Ana & 7 & 13 & 13 & 19 & 14 & 42 & 108 & 8.8 \\
\hline Sonsonate & 3 & 12 & 10 & 15 & 10 & 34 & 84 & 6.8 \\
\hline La Libertad & 3 & 24 & 15 & 27 & 15 & 46 & 130 & 10.6 \\
\hline Chalatenango & 3 & 4 & 4 & 7 & 3 & 22 & 43 & 3.5 \\
\hline San Salvador & 29 & 55 & 75 & 94 & 64 & 45 & 362 & 29.5 \\
\hline Cabañas & 2 & 3 & 3 & 5 & 3 & 16 & 32 & 2.6 \\
\hline Cuscatlán & 2 & 5 & 5 & 8 & 5 & 17 & 42 & 3.4 \\
\hline San Vicente & 2 & 3 & 4 & 6 & 4 & 16 & 35 & 2.9 \\
\hline La Paz & 4 & 8 & 8 & 12 & 8 & 25 & 65 & 5.3 \\
\hline Usulután & 4 & 8 & 8 & 12 & 8 & 35 & 75 & 6.1 \\
\hline San Miguel & 6 & 13 & 15 & 21 & 14 & 21 & 90 & 7.3 \\
\hline Morazán & 1 & 5 & 3 & 6 & 4 & 21 & 40 & 3.3 \\
\hline La Unión & 4 & 6 & 6 & 10 & 6 & 28 & 60 & 4.9 \\
\hline
\end{tabular}




\subsection{El instrumento de la encuesta}

El cuestionario usado para el presente sondeo estaba constituido básicamente por seis partes principales: la primera recogía los datos demográficos de la persona: sexo, edad, escolaridad, situación laboral y religión; además recolectaba información que era llenada por el encuestador referida a ciertas condiciones del entrevistado, tales como estrato socioeconómico, departamento y municipio de residencia; también se preguntaba a los encuestados sobre la frecuencia con que accede a los diferentes medios de comunicación (prensa, radio y televisión).

La segunda parte recolectaba la opinión del entrevistado sobre el principal problema que enfrenta el país; además incluía una serie de interrogantes referidas al problema de la delincuencia, tales como la necesidad de imponer la pena de muerte, la eficiencia de las leyes del país para combatirla, si el gobierno debería establecer leyes más rígidas, quién es el mayor responsable en el control del problema de la delincuencia, la aprobación de la existencia de grupos armados fuera de la ley

Los datos revelan que las familias salvadoreñas serían víctimas de la actividad delincuencial común en mayor medida en el Área Metropolitana de San Salvador (AMSS) que en cualquier otra zona del país. tes, forma de actuar de la institución con respecto a la antigua Policía Nacional, la causa principal por que la que no ha logrado acabar con la delincuencia, sobre el apoyo y respeto de la población hacia la PNC, aprobación del cambio de director, opinión sobre lo que se debe de hacer para combatir el problema de la delincuencia y se pidió además que evaluaran a algunas personas que tienen que ver con las políticas de seguridad pública.

En la sección número cuatro se hicieron preguntas orientadas a recoger información sobre el número de personas que han sido víctimas de un hecho delincuencial, en general, (asalto, robo, extorsión, etc.) en los últimos cuatro meses, el día, la hora y el lugar en donde había ocurrido el hecho y si habían resultado lesionados; también se preguntaba si el encuestado había sido víctima de actos concretos de violencia en un período de doce meses, número de veces que ocurrieron y si denunció el hecho ante cualquier institución. Además se consultó sobre el grado de temor que tienen las personas de ser atacadas o robadas en su casa, calle y lugar de trabajo o estudio. para combatir la criminalidad, la aplicación de los nuevos códigos penal y procesal penal en el control de la delincuencia, las razones por la cuales existe mucha violencia en el país y por qué se da el fenómeno de las maras. En el siguiente grupo de preguntas se pretendía saber cómo las personas evalúan el desempeño de las distintas instancias que tienen que ver con seguridad pública. También recogía las valoraciones que los entrevistados hicieron al gobierno por su interés en combatir la delincuencia, la corrupción, el crimen organizado, el narcotráfico, las maras, la delincuencia común y los secuestros. Para finalizar esta misma parte, se preguntó acerca los delitos que más han aumentado en el país últimamente, las problemáticas de delincuencia que más urge atender, si el gobierno está o no controlando la delincuencia y la aprobación de la creación de grupos de vecinos armados para erradicar la delincuencia por su propia cuenta.

La tercera sección del cuestionario contenía preguntas concretas sobre la Policía Nacional Civil: acerca de la honestidad de la mayoría de agen-
La quinta etapa del cuestionario contenía preguntas relacionadas con las armas: si el entrevistado posee arma de fuego y la razón por la cual la posee, y a los que no tenían se les preguntó si tendrían un arma de fuego para su protección.

La encuesta finalizaba con temas sobre coyuntura política: opinión de quién sería el mejor candidato a la presidencia del país, partido por el cual votaría el entrevistado si las elecciones fueran el próximo domingo y, por último, el partido político con más probabilidades de ganar las elecciones presidenciales de 1999.

En esta entrega, se presentarán los resultados referidos a la victimización de los salvadoreños por causa de la criminalidad, tratando de establecer las características más sobresalientes de aquéllos que son más victimizados; además se presentan los datos referidos a las opiniones sobre la delincuencia que son más sobresalientes. El resto de información puede ser consultada en el informe correspondiente que publica el IUDOP (1998). 


\section{La victimización por la delincuencia común}

Para medir el nivel de victimización que enfrentan los ciudadanos salvadoreños a causa de la delincuencia común, el Instituto Universitario de Opinión Pública utilizó dos formas: la primera exploraba la victimización por la criminalidad común de manera general; la segunda precisaba la victimización por cada tipo de hecho de índole violenta. Así, por un lado, se preguntó a cada uno de los encuestados si él, ella, o su familia habían sufrido de "algún asalto o hecho delincuencial en los últimos cuatro meses"'; en este caso, la victimización se refiere a cualquier delito e incluye a todo el grupo familiar que forma un hogar y circunscribe el marco temporal a cuatro meses. Por el otro lado, la consulta precisaba de manera individual la victimización por los diversos hechos en los cuales había violencia, es decir, uso de la fuerza o amenaza de uso de ésta. En este caso, el lapso de tiempo contemplado era mucho más amplio: un año. Los hechos violentos consultados son: robo violento (iAlguien le robó a mano armada en los últimos doce meses?); extorsión (¿alguien le amenazó para sacarle o pedirle dinero en los últimos doce meses?); golpes (ifue usted golpeado por otra u otras personas en los últimos doce meses?); heridas a causa de armas de fuego y armas blancas (¿fue usted herido con un arma de fuego en los últimos doce meses?; ¿fue usted herido con un arma blanca en los últimos doce meses?); amenazas a muerte (ien los últimos doce meses lo/a amenazaron a muerte a usted o a algún pariente cercano?); secuestro (fue usted o algún pariente cercano secuestrado en los últimos doce meses?); asesinato (¿algún pariente cercano fue asesinado en los últimos doce meses?). A continuación se presentan los resultados de los dos tipos de consulta.

En la primera modalidad de consulta, la encuesta revela una elevada incidencia de hechos delictivos en las familias salvadoreñas. De acuerdo con los datos, el 25.7 por ciento de los salvadoreños habrían sufrido de un asalto o hecho delincuencial ellos o su familia en los últimos cuatro meses antes de la realización de la consulta. Esto implica prácticamente que, al menos, una de cada cuatro familias salvadoreñas habría sido víctima de un hecho delincuencial en un lapso de tiempo no mayor de cuatro meses. Esta proporción indica una incidencia de la actividad delincuencial bastante alta, pero como se verá más adelante no constituye el nivel más elevado que ha sido registrado por las encuestas realizadas en el pasado por el IUDOP. Por el momento es importante hacer notar que la victimización general no parece ser la misma en las distintas zonas del país y en los distintos grupos sociales de los salvadoreños (ver Cuadro 2).

\section{Cuadro 2}

Familias que han sido víctimas de un asalto en los últimos cuatro meses según variables (En porcentajes)

\begin{tabular}{lcc}
\hline \multirow{2}{*}{ Variables } & \multicolumn{2}{c}{ Familias } \\
\cline { 2 - 3 } Todos & No-víctima & Víctima \\
\hline & 74.3 & 25.7 \\
Zona del país & & \\
Occidental & 76.4 & 23.6 \\
Central & 78.4 & 21.6 \\
Metropolitana & 70.3 & 29.7 \\
Paracentral & 77.6 & 22.4 \\
Oriental & 74.3 & 25.7 \\
& & \\
Estrato & & \\
Alto & 71.2 & 28.8 \\
Medio-alto & 73.6 & 26.4 \\
Medio-bajo & 76.3 & 23.7 \\
Obrero & 70.3 & 29.7 \\
Marginal & 68.5 & 31.5 \\
Rural & 79.2 & 20.8 \\
\hline
\end{tabular}

¿Ha sufrido o ha sido víctima Ud. o alguien de los que viven con Ud. de un asalto o de algún hecho delincuencial en los últimos cuatro meses?

Los datos revelan que las familias salvadoreñas serían víctimas de la actividad delincuencial común en mayor medida en el Área Metropolitana de San Salvador (AMSS) que en cualquier otra zona del país. En la zona metropolitana, la victimización por la delincuencia afectaría a casi tres familias por cada diez en un período de cuatro meses, mientras que en otras zonas, como en la cen-

2. La pregunta rezaba exactamente de la siguiente manera: ¿Ha sufrido o ha sido víctima usted o alguien de los que viven con usted de un asalto o de algún hecho delincuencial en los últimos cuatro meses? 
tral, comprendida por los departamentos de Chalatenango, La Libertad ${ }^{3}$ y la zona rural de San Salvador, la delincuencia golpearía a dos familias de cada diez; sin embargo, en el resto de zonas del país, el impacto de la delincuencia final se mantendría más o menos de la misma forma. Por otro lado, los datos ofrecidos por la encuesta revelan que las personas que viven en las zonas urbanas y que pertenecen a los estratos obrero y marginal serían las más afectadas por las actividades de delincuencia; mientras que en las zonas rurales, los niveles de afectación por la violencia delictiva - sin dejar de ser elevados- serían menos graves.

Estos datos ofrecen desde ya una primera aproximación a la fenomenología de la violencia delincuencial. En principio muestran que la gente más afectada por la misma es la que vive en las zonas urbanas del país y la que habita en los barrios y comunidades más pobres de las mismas, aunque no debe despreciarse el fenómeno en otros sectores. Vale entonces pensar que el AMSS, como la mayor zona urbana del país y sus sectores más deprimidos como las marginales y los barrios pobres, serían las áreas geográficas de mayor riesgo de victimización del país. Ello no quiere decir que el problema no exista en las zonas rurales o en las colonias o vecindarios de sectores medios y altos; de hecho, los resultados demuestran que sí hay elevados niveles de victimización en esos lugares, sólo que comparativamente la incidencia del problema es un poco menor. Además, lampoco se puede concluir o sugerir de estos datos de que la pobreza en sí misma estaría asociada al riesgo de victimización: debe recordarse que los niveles de pobreza rural son mucho más alarmantes que los correspondientes a las zonas urbanas del país y, por tanto, siguiendo esa lógica, tendrían que hallarse mayores niveles de victimización en el campo que en la ciudad. Pero los datos no parecen indicar eso, más bien, estarían sugiriendo la importancia de la variable urbana en el fenómeno de la delincuencia.
La pesquisa revela, por otro lado, que los días de la semana en que se dan con menos frecuencia los eventos de victimización son los lunes y los jueves; en el resto de días y sobre todo en el fin de semana, los encuestados reportaron la mayor cantidad de hechos delictivos. Además, en una posible evidencia del carácter urbano de buena parte del fenómeno, los datos señalan que casi el 60 por ciento de los hechos delictivos se dan en las horas de mayor movimiento de salida de las personas de sus empleos, específicamente entre las 10:00 a.m. y la 1:00 p.m., y entre las 5:00 p.m. y las 8:30 p.m.

Alrededor de la cuarta parte de los hechos delictivos ocurren en el centro de las ciudades donde habitan los encuestados y otro porcentaje similar toma lugar en sus vecindarios de vivienda; más aún, el 12.1 por ciento declaró haber sufrido el hecho delincuencial en su propia casa de habitación. Estos datos muestran la ubicuidad del fenómeno de la delincuencia y explican la recurrente queja popular de que "ni en la casa propia se está uno seguro".

Ahora bien, las cifras anteriores son buenas para tener una medida de la victimización general que han sufrido las familias salvadoreñas en un período no mayor de cuatro meses; sin embargo, no ofrece mayor información sobre el tipo de victimización que es más común individualmente entre los salvadoreños. Para cllo, se hizo necesario desarrollar una pequeña batería de preguntas que incluye cada uno de los posibles delitos violentos que pudieron haber sufrido los ciudadanos de manera individual. Los resultados de esta segunda forma de recoger la victimización se exhiben en el Cuadro 3 y revelan que el robo con violencia (19.4 por ciento), la extorsión ( 11.6 por ciento) y las amenazas a mucrte (8.9 por ciento) son los delitos violentos de los que son víctimas los adultos con más frecuencia. No se debe pasar por alto, sin embargo, que otro delito muy grave, como el asesinato de parientes cercanos, muestra un porcentaje de in-

3. En La Libertad se incluyen todos sus municipios a excepción de Antiguo Cuscatlán y Nueva San Salvador. Ios cuales están incluidos en la llamada Área Metropolitana de San Salvador. 
cidencia significativo aunque no constituye uno de los más frecuentes. Los delitos con menor nivel de ocurrencia son el secuestro ( 1 por ciento) y las heridas por armas blancas ( 0.9 por ciento) y armas de fuego ( 0.7 por ciento). Esto no debe confundir la magnitud de este tipo de hechos de violencia. Porcentajes con menos del 2 por ciento pueden parecer insignificantes, pero no lo son si se repara en el hecho de que el 1 por ciento de la población adulta salvadoreña representaría alrededor de 32 mil personas ${ }^{4}$; lo cual significa que una cantidad similar de personas habría sufrido por un secuestro en el lapso del último año antes de la encuesta. Este mismo tipo de proyección apuntaría a que en un año, alrededor de 620 mil personas adultas habrían sido asaltadas. 5

\section{Cuadro 3}

Victimización por distintas causas en el lapso de un año según variables (En porcentajes)

\begin{tabular}{|c|c|c|c|c|c|c|c|c|}
\hline \multirow[b]{2}{*}{ Variables } & \multicolumn{5}{|c|}{ Tipo de hecho } & \\
\hline & $\begin{array}{c}\text { Robo } \\
\text { violento }\end{array}$ & Extorsión & $\begin{array}{l}\text { Golpeado } \\
\text { por otros }\end{array}$ & $\begin{array}{c}\text { Herido arma } \\
\text { blanca }\end{array}$ & $\begin{array}{c}\text { Herido arma } \\
\text { de fuego }\end{array}$ & $\begin{array}{l}\text { Amenazas } \\
\text { de muerte }\end{array}$ & $\begin{array}{l}\text { Secuestro } \\
\text { propio o } \\
\text { de familiar }\end{array}$ & $\begin{array}{l}\text { Asesinato } \\
\text { de familiar }\end{array}$ \\
\hline Todos & 19.4 & 11.6 & 3.2 & 0.9 & 0.7 & 8.9 & I & 5.2 \\
\hline \multicolumn{9}{|l|}{ Sexo } \\
\hline Masculino & 20.7 & 12.6 & 3.7 & 0.5 & 0.7 & 9.1 & 0.5 & 4.9 \\
\hline Femenino & 18.1 & 10.7 & 2.7 & 1.3 & 0.6 & 8.7 & 1.4 & 5.5 \\
\hline \multicolumn{9}{|l|}{ Edad } \\
\hline 18 a 25 años & 24.5 & 14.4 & 5 & 1 & 0.3 & 11.1 & 1 & 4.4 \\
\hline 26 a 40 años & 18 & 9.8 & 3.5 & 0.9 & 0.9 & 9.7 & 0.9 & 6.4 \\
\hline 41 a 55 aก̃os & 17.5 & 12.4 & 1.7 & 0.9 & 0 & 7.3 & 1.3 & 5.6 \\
\hline 56 años y más & 17 & 11.6 & 0.7 & 0.7 & 1.4 & 4.1 & 0.7 & 2 \\
\hline \multicolumn{9}{|l|}{ Estudios } \\
\hline Ninguno & 17.9 & 7.1 & 3.6 & 0.6 & 0.6 & 7.7 & 1.2 & 4.2 \\
\hline Primaria & 15.1 & 9.9 & 1 & 0.5 & 0 & 8.1 & 0.5 & 5.7 \\
\hline Plan básico & 18.8 & 15.6 & 6.5 & 1.6 & 1.1 & 10.3 & 1.6 & 4.3 \\
\hline Bachillerato & 24.2 & 13.8 & 3.8 & 0.8 & 0.4 & 9.2 & 1.2 & 7.3 \\
\hline Superior & 22.6 & 12.2 & 3 & 1.3 & 1.7 & 9.6 & 0.9 & 3.5 \\
\hline
\end{tabular}

¿Quiénes son los ciudadanos que más sufren por acciones de violencia criminal? Examinando el mismo cuadro, se puede ver que en el caso de robo a mano armada, las víctimas más frecuentes son los hombres, las personas más jóvenes y quienes poseen estudios de bachillerato o de nivel superior. Quizás la variable más importante en este punto sea la edad: a medida que las personas tienen más años de edad, en esa medida el porcentaje de victimización por robo a mano armada disminuye, pero los datos muestran que la disminución más radical se da al dejar el grupo de la juventud. En el caso de los hechos de extorsión, los datos reiteran la incidencia mayor entre los hombres que

4. Según las proyecciones de población de la DIGESTYC, et al. (1997), para 1998 la población adulta nacional rondaría los 3 millones 200 mil personas.

5. Este ejercicio de proyección no pretende ofrecer cifras concluyentes dado que el estudio no fue probabilístico y, por tanto, no es posible aplicar técnicas de expansión a los datos de la muestra; sin embargo, el mismo ofrece una idea de la magnitud del problema al pensar en términos absolutos y no en términos de porcentajes. 
entre las mujeres y entre los jóvenes más que entre las personas de otros grupos de edad; pero revelan que un ciudadano con un nivel básico de formación educativa se vuelve más propenso de sufrir este tipo de delito que otra persona con ninguna o con bajo nivel escolar. Otros delitos de violencia como las amenazas a muerte y los golpes se dan también con más frecuencia en los hombres que en las mujeres y en los jóvenes más que en cualquier otro grupo de edad. Al final, estas tendencias en la victimización por distintas causas confirmarían un fenómeno ya consignado por otros estudios sobre la violencia en El Salvador y Latinoamérica, esto es, que los hombres y los jóvenes constituyen las víctimas más frecuentes de la violencia en la actualidad (Cruz, 1998; Yunes y Rajs, 1996).

\subsection{La victimización por delincuencia común en perspectiva}

El hecho de que uno de cada cuatro hogares salvadoreños haya sido objeto de hechos delincuenciales en los últimos cuatro meses es de suyo un dato que muestra un elevado nivel de delincuencia. Sin embargo, una comparación con datos recogidos en sondeos anteriores muestra que estos porcentajes de victimización por delincuencia no son los más altos que ha tenido el país en los últimos cinco años'. Es más, la comparación temporal entre los años 1993 y 1998 revela que el fenómeno de la violencia criminal, al menos aquélla de la cual es víclima el salvadoreño promedio, no ha crecido sino que inclusive podría estar disminuyendo. La Gráfica I señala que, según una encuesta realizada en febrero de 1993 por el IUDOP, el 31 por ciento de las familias a nivel nacional fue víctima de algún hecho criminal en un lapso de cuatro meses; para agosto del siguiente año, otra encuesta indica que el porcentaje asciende al 35 por ciento, más de la tercera parte de las familias salvadoreñas; para mayo de 1996, el porcentaje reportado por la encuesta de esa fecha, 26.4 por ciento, revela una disminución sustancial; y en la medición correspondiente a esta encuesta realizada en julio del 98 , el porcentaje de familias victimizadas a nivel nacional se mantiene casi igual, 25.7 por ciento.
Según esta tendencia, basada en las declaraciones de los ciudadanos, la victimización por delincuencia común, medida en períodos de cuatro meses, no habría crecido desde 1994, más bien habría bajado. Esta tendencia es nacional y ello implica un comportamiento parecido en lo que se refiere a las zonas urbanas -donde la delincuencia parece ser siempre más alta- y a las zonas rurales. En otras palabras, no hay evidencias de que la criminalidad común haya aumentado en comparación con años anteriores.

\section{Gráfica 1}

Tendencias de victimización a nivel nacional por algún hecho delincuencial

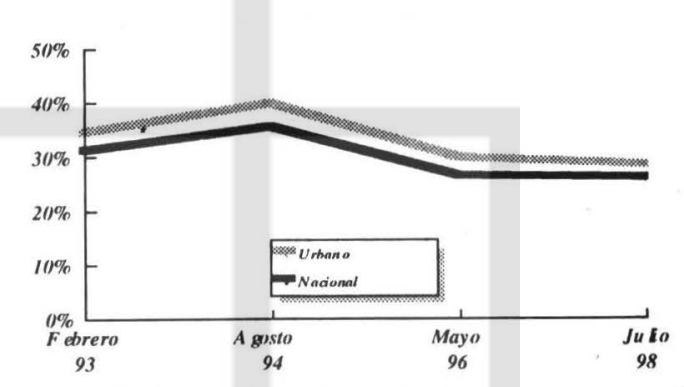

Fuente: Elaboración sobre distintas encuestas del IUDOP

La importancia de estas cifras es clara. En principio pone en duda la impresión - y a veces casi convicción- de que la incidencia de la criminalidad común está creciendo en el país, y muestra que en el pasado próximo los salvadoreños han enfrentado niveles de victimización más altos que los que debe enfrentar en la actualidad. Esto no quiere decir que la victimización por delincuencia no sea grave en 1998, como tampoco quiere decir que las expresiones de la criminalidad, esto es, los hechos de violencia, sean menos severos y letales; los datos sólo muestran que el porcentaje, y por tanto el número, de familias asaltadas no ha subido en los últimos dos años.

Estas tendencias de victimización, recogidas por las encuestas de opinión pública del IUDOP,

6. Esta comparación es posible dado que todas las encuestas se hicieron siguiendo el mismo procedimiento metodológico de muestreo (aunque en 1993 la investigación sólo se remitió al área urbana) y una formulación de la pregunta de victimización muy similar. 
siguen la misma orientación de disminución en los homicidios a nivel nacional y metropolitano registradas por la Fiscalía General de la República y por las alcaldías metropolitanas (ver Cruz y González, 1997; Portillo, 1998), lo cual respaldaría la tesis de que la violencia no está subiendo en el país en comparación con años pasados.

\section{Las denuncias y las instituciones}

\subsection{Las denuncias}

Otro dato que es tan importante como el de la victimización por delincuencia es el que se refiere al porcentaje de población que denuncia ante las autoridades los hechos criminales sufridos. $\mathrm{Y}$ es igualmente importante porque revela varias cosas. En primer lugar, muestra el involucramiento de las personas en la tarea de perseguir y combatir el fenómeno del crimen y, en segundo lugar, revela en cierta forma el nivel de confianza que la población tendría en los mecanismos institucionales para resolver los hechos de violencia criminal de los cuales se ven afectados.

La encuesta del IUDOP muestra que sólo el 29.2 por ciento de las familias salvadoreñas denunciaron el hecho delincuencial que sufrieron en los últimos cuatro meses antes de la encuesta, es decir, de cada diez hechos, sólo tres fueron denunciados ante las autoridades. La mayor parte de las denuncias, el 94.6 por ciento, fue presentada a la Policía Nacional Civil', mientras que el resto fueron presentada ante otras instituciones de justicia, los tribunales o la Fiscalía. Las personas que, según los datos de la pesquisa, suelen utilizar más los mecanismos de denuncia son aquéllas que pertenecen a los estratos más acomodados de la población —en el estrato alto, el porcentaje de denuncia alcanza $\mathrm{cl} 52.4$ por ciento de los hechos$y$, curiosamente, los que simpatizan políticamente con el partido del gobierno. En el otro lado de la moneda, los menores índices de denuncia pueden encontrarse entre los residentes de la zona occidental del país, entre los habitantes de las comunidades marginales —en estas zonas, la encuesta reporta sólo un 19.4 por ciento de denuncias-y entre las personas mayores de 55 años de edad (ver IUDOP. 1998).

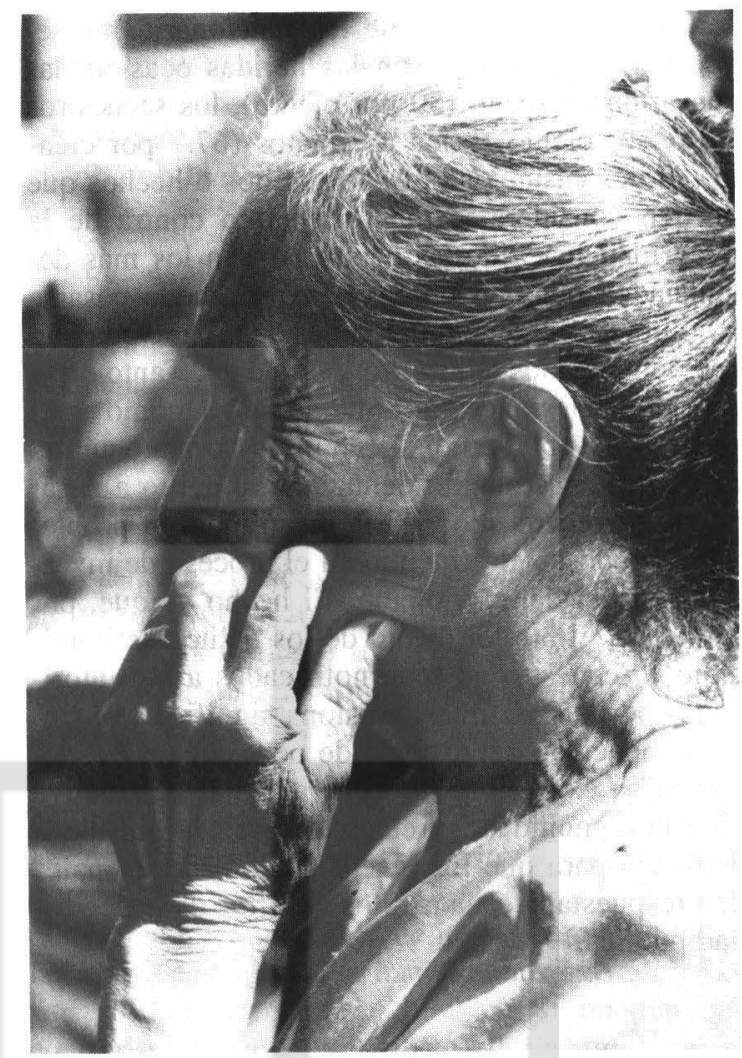

Pero, el porcentaje de denuncia de un hecho criminal no sólo varía en función de las caracteríslicas de la víclima o del lugar donde fue cometido el delito; la conducta de declarar varía en función del tipo de hecho del cual las personas fueron víctimas. En la Gráfica 2 se presentan los porcentajes de denuncia de cada uno de los hechos violentos sufridos por los ciudadanos en el último año. Según el mismo, el delito que menos se denuncia ante las autoridades correspondientes es el de extorsión (amenazas para sacarle o pedirle dinero), con sólo un 22.4 por ciento de víctimas que aseguran haber puesto hecho la denuncia correspondiente; le sigue el robo a mano armada, el cual es denunciado un poco más, por el 30.7 por ciento; las agresiones por golpes y las amenazas a muerte son denunciadas por la tercera parte de la población, aproximadamente, y los ataques que dejan heridas de arma blanca son notificados a los organismos policiales en un 36.4 por ciento. Los delitos que

7. Debe recordarse de que la encuesta fue realizada a pocos meses de haber entrado en vigor la nueva normativa penal y procesal penal que otorga a la Fiscalía General de la República la facultad de investigar los delitos. 
son más denunciados ante los funcionarios de seguridad y de justicia son las heridas ocasionadas con arma de fuego (50 por ciento), los secuestros (61.5 por ciento) y los asesinatos (67.7 por ciento). No es casualidad que los delitos o hechos que pueden considerarse más graves en contra de la integridad física de las personas sean los más denunciados por la víctima; pero no puede pasarse por alto el hecho de que a pesar de tal gravedad no son denunciados en un cien por ciento. Tanto en el caso de las lesiones por arma de fuego, como en el secuestro y homicidio, queda un importante número de personas que no denuncian el delito a pesar de su gravedad; ello estaría mostrando un problema serio desde el principio en el proceso de investigación del delito violento. El hecho de que, por lo menos, el 30 por ciento de los delitos de homicidio y secuestro no sean notificados a las autoridades por sus víctimas, erosiona significativamente la capacidad del sistema de persecución del delito en su expresión más severa y más destructiva para la comunidad, y rebaja el nivel de presión o demanda para que los mecanismos institucionales den respuesta adecuada a los desafíos de la seguridad pública.

\section{Gráfica 2}

Porcentajes de denuncia a las autoridades por tipo de delito violento sufrido

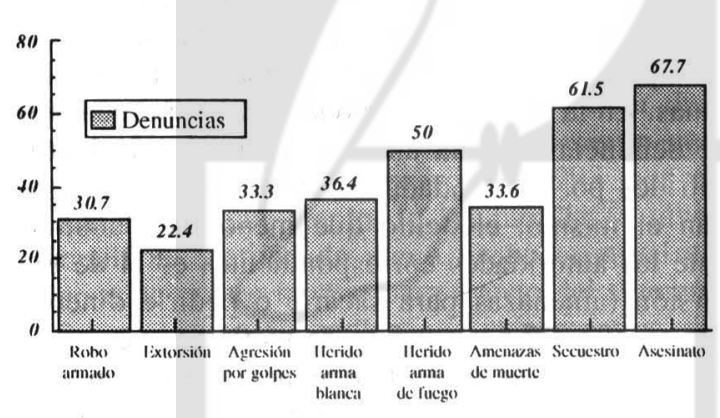

Ahora bien, ¿por qué razón la mayor parte de los ciudadanos no denuncia los hechos criminales de los cuales son víctimas? La encuesta de la UCA preguntó directamente a los encuestados las razones que tenían para no denunciar el hecho, así como también indagó sobre las implicaciones de denunciar el hecho violento o los resultados de la denuncia. Al final, las respuestas hacia ambos tipos de cuestionamientos llevan a lo mismo: desconfianza hacia el sistema.
Casi la mitad de las personas (50.7 por ciento) que no denunciaron el evento criminal afirmó que "es por gusto", las autoridades no hacen nada; el 14.3 por ciento se remitió al hecho de que no tenían pruebas suficientes para poner la denuncia; el 13.5 por ciento expresó temor de sufrir represalias si denunciaba el delito y un 12.6 por ciento no le dio importancia al suceso por lo que decidió no presentar el aviso ante las autoridades, el resto de encuestados ofrecieron otras razones. Un análisis sobre los datos anteriores muestra que lo que prevalece es el escepticismo de que las autoridades sean capaces de hacer algo y esto impide que muchas personas se decidan a utilizar los canales institucionales para denunciar el delito; este escepticismo aparece más o menos con la misma intensidad en todos los sectores sociales y en todos los grupos demográficos estudiados, por lo que la desconfianza estaría relativamente generalizada. A esto habría que agregar el hecho de que algunas personas no denuncian el agravio criminal por temor a sufrir represalias ("porque es peligroso"); ello significa que no están convencidas de la capacidad del mismo sistema para proveerles seguridad si ellos deciden notificar a las autoridades. Al final, el sentimiento de muchos ciudadanos parece ser el de desamparo: no se denuncia porque no se tiene la seguridad de que servirá para algo, y cuando se denuncia no se tiene la seguridad sobre la propia integridad física.

A la raíz de lo anterior probablemente se halla la propia experiencia pasada sobre el desenlace de las denuncias, algo que también documenta la encuesta en cierta medida. A estas personas que denunciaron el asalto o hecho criminal se les preguntó por el resultado de la denuncia. Los datos son nuevamente muy expresivos. Más de la mitad de los ciudadanos que notificaron el delito a las autoridades expresaron que las mismas "no han hecho nada" (ver Gráfica 3); esta opinión es más frecuente entre los sectores socioeconómicos mediobajos y entre las personas que no tienen formación educativa alguna. En esa misma línea, el 14.3 por ciento de los denunciantes declaró que no se han enterado del resultado de las investigaciones o que no han sido notificados del avance de las mismas por parte de las autoridades; éste tipo de respuesta aparece más común entre los campesinos o habitantes de las zonas rurales. En el otro lado de la moneda, cerca del 30 por ciento de las personas que denunciaron el acto criminal han visto resultados positivos: el caso se ha resuelto satisfactoria- 
mente ( 16.5 por ciento) o los encuestados saben que se está haciendo una investigación sobre el mismo (13.2 por ciento).

\section{Gráfica 3}

Resultado de la denuncia del delito sufrido ante las autoridades

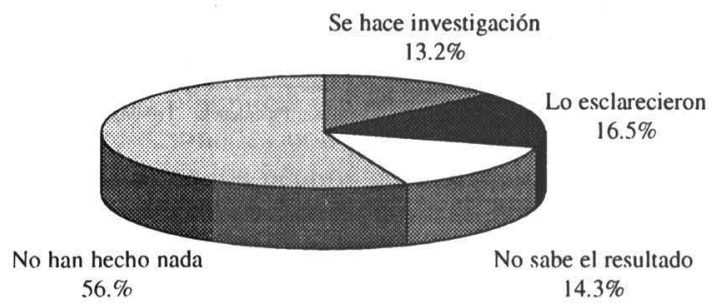

Lo anterior significa, sin embargo, que desde la opinión de los denunciantes", de cada cien denuncias que son hechas a las autoridades -especialmente a la policía- al menos treinta serían atendidas y la mitad de ellas serían esclarecidas para satisfacción del denunciante. En el fondo, estos datos no sólo estarían recogiendo el porcentaje de casos atendidos debidamente por las autoridades y probablemente el porcentaje de eficiencia de las mismas, sino que sobre todo estarían registrando la percepción sobre la eficacia de las autoridades para perseguir el delito. Si la población percibe que la fuerza pública no es capaz de "hacer nada" en los casos concretos de denuncias presenladas, la credibilidad en las autoridades se pierde sustancialmente, lo que conduce a que en futuras situaciones similares no se acuda a las instancias respectivas. Al final, se suman actitudes que llevan a que la mayor parte de la población continúe sin hacer uso de los canales institucionales para hacer frente a la delincuencia.

Todo lo anterior lleva a preguntarse por la manera en que los salvadoreños ven el desempeño de las instituciones encargadas de lidiar con el problema de la violencia delincuencial que azota al país, esto es, las instituciones de seguridad pública y de administración de justicia.

\subsection{Evaluación sobre las instituciones que com- baten la delincuencia}

La encuesta de la UCA pidió a los salvadoreños que evaluaran el desempeño de algunas instituciones nacionales relacionadas con el combate de la violencia y la delincuencia. Las instituciones evaluadas fueron: la Policía Nacional Civil, los tribunales de justicia, el Ministerio de Seguridad Pública, la Fiscalía General de la República y la Procuraduría para la Defensa de los Derechos Humanos. Se incluyó también dentro de la evaluación a la Presidencia de la República que, aunque su mandato no se limita al campo de la seguridad ciudadana, constituye a través del Ministerio en cuestión, la instancia máxima responsable de las políticas de combate a la criminalidad en el país.

En general, las evaluaciones institucionales que hace la población salvadoreña son más positivas de lo que se hubiera esperado en función de la reticencia de los ciudadanos de acudir a las instituciones para denunciar los delitos. Aunque no todas las opiniones sobre las instituciones salvadoreñas son abrumadoramente favorables, sí pueden encontrarse instituciones que reciben un significativo respaldo por parte de los salvadoreños en la lucha contra el crimen. Por ejemplo, la Policía Nacional Civil y la Procuraduría para la Defensa de los Derechos Humanos - precisamente las dos instituciones creadas por los acuerdos de paz de 1992reciben juicios positivos sobre su trabajo provenientes de un poco más de la mitad de la población encuestada. Sin embargo, en el resto de instituciones, las valoraciones positivas sobre el desempeño institucional no van más allá de la mitad de las opiniones recogidas y, en varias de ellas, predominan las evaluaciones negativas. El 44.1 por ciento de los encuestados evalúa de forma positiva al Ministerio de Seguridad Pública, mientras que el 41.2 por ciento hace lo mismo con respecto a la Fiscalía. Las instituciones que son evaluadas menos positivamente -e incluso puede considerarse que son vistas de manera negativa - son la Presidencia de la República y los tribunales de justi-

8. Se enfatiza esta condición "desde los denunciantes" porque lo que se están recogiendo son opiniones, no hechos en sí mismos, es posible, por tanto, que alguna denuncia sea atendida debidamente sin que de ello tenga conocimiento y conciencia plena el denunciante. 
cia, con valoraciones favorables inferiores al $\mathbf{4 0}$ por ciento de la población.

Es curiosa la diferencia en las evaluaciones entre la presidencia nacional y el Ministerio de Seguridad Pública, pues ambas instituciones se mueven en el mismo espacio de responsabilidades políticas. La divergencia en las opiniones podría explicarse -hipotéticamente- en el componente político que evoca la figura de la presidencia; en otras palabras, podría ser que algunas de las valoraciones de los salvadoreños sobre el desempeño del presidente como responsable de las políticas de combate a la delincuencia estén más impregnadas de las posturas ideológicas y políticas de los ciudadanos que de una apreciación del desempeño del presidente en esta área. En todo caso, la distancia que toma la gente de la institución presidencial dice además sobre el desencanto hacia el ámbito político que está detrás de las actuaciones frente al fenómeno de la delincuencia.

Las opiniones favorables respecto al trabajo de la policía y la defensoría de derechos humanos probablemente estén reflejando, por un lado, la consideración que los ciudadanos dan a las instituciones que entran en contacto con ellos con más frecuencia. Tanto la Policía Nacional Civil como la Procuraduría para la Defiensa de los Derechos Humanos constituyen corporaciones que se encuentran más al alcance de los ciudadanos que el resto de instancias evaluadas. Además, en el caso concreto de la PNC, es obvio que esta institución es la única cuyo mandato esencial tiene que ver con el combate a la criminalidad, y quizá por ello la gente le atribuye una evaluación más positiva.

Ahora bien, el estudio reveló que la evaluación de los ciudadanos sobre las instituciones se encuentra vinculada significativamente con la condición de haber sido víctimas o no de algún hecho de violencia entre los investigados por la encuesta. Es decir, las personas que no han sufrido delito alguno en el último año, expresaron opiniones más

\section{Gráfica 4}

Evaluación positiva de las instituciones relacionadas con el combate del crimen

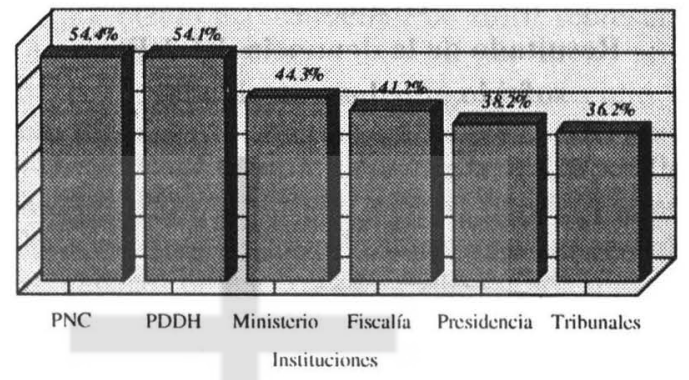

favorab!es hacia las instituciones evaluadas, en tanto que las personas que enfrentaron al menos un hecho de violencia en el mismo lapso presentaron opiniones menos positivas, y las personas que han sufrido varios delitos en el transcurso de un año no evalúan bien a las autoridades". Este efecto se presenta en la evaluación de todas las instituciones, pero es especialmente fuerte en el caso de la Policía Nacional Civil y de los juzgados. Por ejemplo, el 58.3 por ciento de las personas que no fueron víclimas de delito alguno en el último año evaluaron de manera positiva a la PNC; mientras que el porcentaje baja a 52.6 en el caso de los que sí sufrieron un hecho delincuencial en el lapso de un año, y a 44.8 por ciento entre quienes han estado expuestos a repetidos actos de violencia en el mismo período. En el caso de los juzgados, la evaluación disminuye de un 41.2 por ciento en el caso de los no victimizados a un 28.1 por ciento en el caso de aquéllos victimizados frecuentemente. Todo lo anterior significa que parte de la evaluación sobre las instituciones se fundamenta en las propias experiencias relacionadas con la delincuencia. En otras palabras, la efectividad de las instituciones se mide, en parte, en función de que la persona haya sido expuesta a un evento criminal. Esta interpretación se fundamenta simplemente en el análisis cuantitati-

9. Para el caso, se agruparon a las personas de la siguiente manera: un grupo estaba constituido por aquéllos que no han sulrido delitos en el último año; otro grupo reunía a las personas que sufrieron al menos un delito, y otro más reunía a las personas que enfrentaron dos delitos o más en el mismo año. 
vo de los hechos de violencia, pero es muy probable que si se hubiese considerado el tipo de delito en el análisis, tomando en cuenta que cada tipo de delito tiene un impacto diferente en la víctima por ejemplo, es muy distinto ser víctima de un robo a mano armada que haber sido secuestrado - es posible que las variaciones en las evaluaciones hubiesen sido más grandes.

Sin embargo y por otro lado, a pesar de la vinculación de las opiniones institucionales con las experiencias de victimización, la pesquisa de la UCA muestra que tales opiniones - al menos como han sido obtenidas por el sondeo- no se encuentran relacionadas con la conducta y la disposición a denunciar los hechos de violencia sufridos. Tanto las personas que denuncian los hechos como aquéllos que no lo hacen muestran los mismos juicios de valoración sobre el trabajo de las instituciones y no es posible, a partir de estos datos, vincular la actitud de denuncia de los ciudadanos con la visión sobre las instituciones. En otras palabras, parece que la decisión de acudir a denunciar no tiene que ver significativamente con una percepción menos negativa del trabajo de las instituciones; los que van a denunciar acudirían movidos por otras razones - como el lipo de delito sufrido-, pero no porque vean a la institución de manera más favorable. Al final, parece claro que los que han sufrido por la delincuencia comparten una visión más negativa acerca de las instituciones y esto probablemente constituye la razón principal para que la mayoría de las víctimas decidan en principio no notificar a las autoridades.

\section{Las opiniones y actitudes sobre el problema de la delincuencia}

Prácticamente nadie pone en duda de que la delincuencia y la violencia criminal constituyen en la actualidad un problema serio. Más de mitad de las personas encuestadas, el 52.9 por ciento, señalaron a la delincuencia y la violencia como los principales problemas del país, por encima de otras dificultades también consideradas importantes por la población (los problemas de índole económico). La encuesta de la UCA se hizo en un momento en que la sociedad salvadoreña estaba debatiendo nuevamente, a través de los medios de comunicación, acerca de las formas de enfrentar el problema, por lo que los resultados de esta encuesta en lo que liene de opiniones reflejan ese debate.
Aparte de la conciencia generalizada de que la delincuencia es un problema grave, existe otro consenso en la opinión pública sobre la tendencia de la problemática. Al preguntar directamente sobre la situación de delincuencia en el país, ocho de cada diez ciudadanos piensan que en los últimos años el problema de la delincuencia ha aumentado; uno de esos diez tiene la idea de que "no es que la delincuencia haya aumentado, lo que sucede es que ahora la gente está más preocupada", y otro de esos diez piensa que están sucediendo ambas cosas: la delincuencia ha aumentado, pero también piensa que ahora hay más gente preocupada. Más aún, a juzgar por las expresiones de la gente, la idea central no es simplemente de que ahora existe más criminalidad que antes, la idea fundamental es que el fenómeno sigue creciendo sin detenerse y sin que puedan avizorarse formas de solución. De ahí que el 72.3 por ciento de los ciudadanos —en una opinión que tiene también un amplio consentimiento- - sostengan que el gobierno no está logrando controlar la delincuencia por varias razones (incapacidad, falta de voluntad, le-

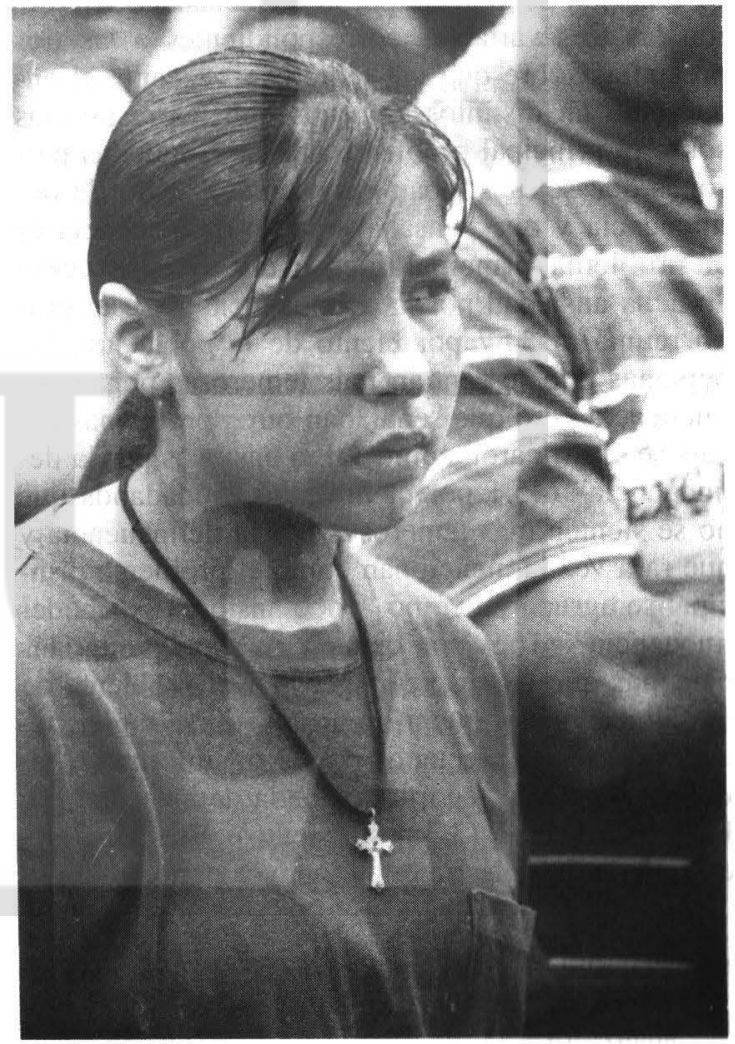


yes no adecuadas, etcétera). Buena parte de las opiniones se concentran en culpar a las leyes - tanto las antiguas como las que se refieren a los nuevos códigos penal y procesal penal- de la falta de efectividad para terminar con el crimen: el 69.5 por ciento cree que las leyes del país no sirven para acabar con la delincuencia.

En todo caso, este tipo de pensamiento social está acompañado de un fuerte componente emocional, no es sólo que la población salvadoreña exprese ahora que hay más delincuencia y que esté convencida de que no se está haciendo nada por detenerla, es también que muchos ciudadanos están asustados por la posibilidad de ser víctimas de la misma. El sondeo preguntó a los ciudadanos sobre qué tan temerosos se sienten de ser atacados o de sufrir un asalto en el hogar, en la vía pública y el trabajo. En los tres casos, más del 55 por ciento de los encuestados se sienten más temerosos que antes de sufrir un asalto, y el lugar donde la gente se siente más temerosa es en la vía pública, fuera del hogar o del trabajo.

Para poder tener una medida del sentimiento de aflicción de la gente por la delincuencia, se unieron las tres variables correspondientes a las tres preguntas sobre qué tan temeroso se siente el encuestado en distintos entornos con las respuestas sobre el principal problema del país: aquellas personas que se mostraban muy temerosas por la delincuencia y que pensaban que la delincuencia es el problema principal fueron clasificadas como "mucha ansiedad por la delincuencia", y este grupo reunía al 34.7 por ciento de la población; las personas que se sentían más temerosas por la delincuencia pero que señalaban otros problemas del país se clasificaron como "algo ansiosos por la delincuencia" (45.1 por ciento); los ciudadanos que no se sienten más temerosos por la delincuencia y que rara vez la mencionan como el problema principal se agruparon como "poco ansiosos por la delincuencia" (16.9 por ciento); y, finalmente, las personas que no se preocupan por el problema de la delincuencia y que afirmaron sentirse menos temerosos de ser afectados por la misma fueron reunidos bajo la categoría de "nada de ansiedad por la delincuencia" (3.3. por ciento). En principio, este ejercicio muestra que la mayor parte de la po- blación, casi el 80 por ciento de los encuestados, vive con niveles altos de ansiedad a causa de la delincuencia, lo que significa que quienes no están preocupados o afligidos por la delincuencia constituyen una minoría de la población salvadoreña; en otras palabras, no es una exageración decir que los salvadoreños viven atemorizados por la posibilidad de ser afectados por la violencia criminal.

Ahora bien, siempre se ha dicho que una ciudadanía temerosa tiende a pedir medidas más drásticas que una colectividad que vive sin temor. Para establecer el impacto de la ansiedad por la delincuencia en las opiniones que apoyan medidas más enérgicas para combatir las leyes, se cruzaron los datos referidos al sentimiento de aflicción por la delincuencia con las opiniones favorables a medidas y conductas más drásticas —algunas incluso ilegales. En principio, las opiniones a favor de acciones más duras para detener la delincuencia reciben amplios porcentajes de apoyo por parte de toda la población, inclusive aquellas acciones que son ilegales, como tomarse la justicia por su propia mano o apoyar a grupos como la "Sombra negra". Casi por unanimidad, los salvadoreños están a favor de leyes más rígidas para combatir el crimen (90.6 por ciento); el 54.2 por ciento apoya la reinstalación de la pena de muerte; en un dato más preocupante, un poco más de la mitad piensa que la "gente tiene el derecho de tomarse la justicia por sus propias manos"; otro porcentaje similar (48.9 por ciento) favorece la formación de juntas armadas de vecinos, y un poco más de la tercera parte ve con buenos ojos la presencia de grupos armados ilegales que hacen limpieza social. Además, la mitad de los encuestados desearía adquirir un arma para su protección. A pesar de ello, es posible encontrar diferencias en este tipo de opiniones, lo cual depende del grado de ansiedad o temor que tengan los ciudadanos a causa de la criminalidad: a medida que las personas presentan un mayor grado de ansiedad, en esa medida tienden a sostener con más frecuencia opiniones que favorecen distintos tipos de medidas drásticas. Aunque no en todos los casos las diferencias son respaldaJas estadísticamente ${ }^{10}$ y algunas de ellas no llegan a ser tan pronunciadas, los datos muestran con consistencia de que a mayor ansiedad por la situa-

10. De hecho se aplicó una prueba de Chi-cuadrada para establecer si las diferencias en las frecuencias son significativas estadísticamente. La prueba dio valores correspondientes a una $p<0.05$ sólo en dos casos de los seis analizados. 
ción de delincuencia, mayor apoyo a las medidas enérgicas para combatirla. Estas diferencias poco pronunciadas en algunos casos se explicarían por el bajo porcentaje de personas que en realidad no viven preocupadas por la posibilidad de ser afectados por la violencia criminal".

Ahora bien, todos estos datos muestran que el nivel generalizado de ansiedad por el crimen hace que las opiniones que prevalezcan sean las que reclaman mayor dureza en las medidas y en las penas para combatir la delincuencia; la sociedad salvadoreña, en este sentido, estaría "dominada" por una opinión que reclama más severidad en el tratamicnto del crimen como producto del intenso sentimiento de temor y de inseguridad. En esta línea, mucha gente no sólo parece estar dispuesta a endurecer las leyes — como parece ser la opinión más generalizada - sino que además estarían dispucstos a apoyar medidas que van totalmente en contra de la legalidad, la institucionalidad y el respeto a las garantías ciudadanas. Bajo este sentimiento de ansiedad, la gente estaría más dispuesta a apoyar la pena de muerte y estaría más inclinada a aplaudir a grupos de limpieza social como la "Sombra Negra"; más aún, probablemente los datos estén incluyendo a algunos que estarían dispuestos a formar parte de tales grupos. También, bajo el sentimiento de ansiedad, es posible que mucha gente tenga menos problema para justificar la posesión de arma de fuego, formar juntas armadas para combatir la delincuencia y reclamar la libertad de tomarse la justicia por su propia mano. Hay que recalcar, no obstante, que ello no quiere decir que toda la gente que está más preocupada por la delincuencia va a pensar o inclusive a actuar de esa manera; más bien significa que las probabilidades de encontrar personas que sí lo harían son mayores.

\section{Cuadro 4 \\ Opiniones a favor de algunas medidas para combatir la delincuencia según niveles de preocupación por la misma \\ (En porcentajes)}

\begin{tabular}{llllll}
\hline & & \multicolumn{4}{c}{ Nivel de ansiedad por la delincuencia } \\
\cline { 2 - 6 } Medidas para combatir el crimen & Todos & Mucho & Algo & Poco & Nada \\
\hline A favor de leyes más rígidas & 90.6 & 92.1 & 90.9 & 86.9 & 86.5 \\
Apoya pena de muerte * & 54.2 & 61.0 & 52.0 & 48.9 & 37.5 \\
Reclama el "derecho" de tomar justicia por propia mano & $5 l .9$ & 55.3 & 50.1 & 51.3 & 44.4 \\
Apoyan formar juntas de vecinos armados & 48.9 & 51.9 & 50.5 & 40.3 & 37.8 \\
De acuerdo con grupos ilegales armados * & 36.9 & 43.3 & 35.4 & 30.4 & 24.3 \\
Quisiera tener arma de fuego & 50.8 & 53.8 & 50.5 & 48.6 & 34.3 \\
\hline
\end{tabular}

$* p<0.05$

5. Reflexiones sobre la delincuencia y la opinión pública

Quizás la reflexión más importante que cabe hacer a partir de los datos anteriores es que bajo un sentimiento generalizado de ansiedad y temor por la delincuencia, en el fondo los ciudadanos estarían más dispuestos a acudir a la violencia como forma de combatir el mismo crimen violento. Acu- dir a la pena de muerte, aunque legitimada legalmente; apoyar a grupos de limpieza social que se dan a la tarea de eliminar delincuentes, y la necesidad de poseer un arma como forma de protección constituyen conductas o actitudes que privilegian el uso de la violencia como método de hacer frente a la misma. Ello confirma el principio de reproducción de la violencia e indirectamente advierte

11. El hecho de que la mayoría de los ciudadanos está en el grupo de personas con mucho o algo de preocupación por la delincuencia hace que el resto de grupos sea muy pequeño. lo que aumenta la varianza en los resultados y alecta el poder de la prucba estadística para medir adecuadamente la relación. 
sobre la complejidad de un fenómeno que parece ubicuo y que ha rebasado los límites del control.

Buena parte de la sociedad salvadoreña está tan preocupada por el problema de la delincuencia que no se ha dado cuenta de que sus mismas respuestas al fenómeno no hacen sino contribuir a la permanencia del mismo. Muchos de los asesinatos $y$ hechos de violencia cometidos diariamente en el país no parecen estar vinculados a lo que usualmente se conoce como delincuencia - aunque la mayor parte de actos violentos son delitos-; muchos hechos que terminan en muerte y lesiones no están motivados por la intención de obtener dinero, sino por represalias, venganzas o actos de limpieza social. Según el registro de muertes violentas informadas por la prensa llevadas por el IDHUCA en 1996, el 56 por ciento de las mismas no habían sido en circunstancias de delincuencia común, sino en condiciones no identificadas, por móviles desconocidos o por escuadrones de la muerte o grupos de limpieza social.

La ansiedad por la violencia afecta la confianza de los ciudadanos en los demás, sobre todo en las personas que parecen diferentes; en eso se fundamentan las prácticas de limpieza social que parecen estar tomando auge en la actualidad con los asesinatos de homosexuales o con la aparición del llamado "matabolos"; además erosionan las redes de interacción social en la comunidad, el trabajo o en la vía pública, y estimula conductas de recelo y agresión hacia los desconocidos y de castigo hacia los sospechosos.

Pero, ¿a qué se debe esta percepción de que la delincuencia es peor ahora que en el pasado y este sentimiento tan generalizado de ansiedad que parece no corresponder con una realidad que indica que el país no enfrenta más violencia criminal que la que enfrentó hace tres o cuatro años? Los factores intervinientes pueden ser muchos. Para comenzar, se debe reconocer que el problema es muy grave y que ello constituye el principio fundamental de la actitud ciudadana; sin embargo, esta actitud no parece moverse con las tendencias más o menos objetivas de los hechos. Las encuestas de opinión pública reflejan que la preocupación por la delincuencia, en la actualidad, es mucho mayor de lo que era en 1994 y, sin embargo, las encuestas no ofiecen evidencias de que haya más gente asaltada ahora que lo que había en el pasado.
Sin duda no debe dejarse de prestar atención al rol de la prensa. Los medios de comunicación prestan en la actualidad mayor atención al problema de la delincuencia que en el pasado; pareciera que en años anteriores, los redactores de la noticia salvadoreña no habían caído en la cuenta de la magnitud del problema salvadoreño. En la actualidad - y sin tener un dato preciso-, la mayor parte de informaciones se dedican a señalar y documentar, a veces de forma exacerbada, los niveles de violencia que sufre el país. Un estudio realizado también por el IUDOP (ver Cruz, 1996) reveló que las opiniones sobre la delincuencia como el principal problema del país dependen del nivel de exposición a la prensa escrita y televisada que tienen los ciudadanos: a mayor atención a los medios, más convicción de que la delincuencia es el problema fundamental. Los datos recabados por esta investigación se orientan a la misma tendencia.

La responsabilidad de los medios estaría en la transmisión de una imagen sobre el país extremadamente alarmante y hostil que, en el afán de ser un producto de consumo masivo que estimula el morbo, atemoriza a los ciudadanos porque no da espacios a la reflexión de las causas y las responsabilidades de la violencia criminal. Al final, el público queda convencido de que las mejores formas de evitar la violencia son, por un lado, no meterse en nada y ello implica incluso no denunciar los propios asaltos sufridos; y, por otro lado, protegerse individualmente ignorando a los demás de quienes además se sospecha- e ignorando que la seguridad pública se construye en conjunto.

Sin embargo, los medios de comunicación no tienen toda la responsabilidad en la ansiedad social por la delincuencia. El impacto mayor sobre la preocupación ciudadana sobre la delincuencia estaría más bien en la propia experiencia de la gente, en el efecto acumulador de las mismas y en la acumulación de frustraciones por la ausencia de respuestas efectivas al problema. En otras palabras, los ciudadanos estarían respondiendo en función a que con el paso del tiempo son víctimas una y otra vez de los hechos de violencia y de que, a pesar de la importancia reconocida del problema, ésta no ha podido solucionarse como se esperaba. Para entender este cansancio es importante recordar que la violencia no es nueva para los salvadoreños; ya en décadas anteriores éstos reclama- 
ban seguridad frente a la violencia social, frente a la violencia bélica. La ola delincuencial ha renovado la permanente expresión de la violencia y ha mostrado a los ciudadanos que siguen estando tan expuestos a la misma como en el pasado, sobre todo y paradójicamente, a partir de un momento del cual esperaban totalmente lo contrario (los acuerdos de paz).

El problema de la delincuencia, así como el de la violencia en general, es un problema grave en El Salvador, de eso no hay duda. Pero la persistencia del mismo, el manejo del tema por parte de algunos agentes sociales y la frustración ciudadana por la falta de soluciones están llevando a buena parte de la población a algo muy cercano a la desesperación, la cual está provocando que muchas personas apoyen o busquen respuestas alternativas, basadas también en la violencia, y que someten a la sociedad salvadoreña en un estado de enfrentamiento continuo, difuso e informal (IUDOP, 1996b). Esto puede convertirse o ser ya un círculo vicioso, una espiral dominada por la lógica reproduclora de la violencia, pero puede y debe detenerse y ello será posible, en parte, si se acude a la razón y no a la fuerza.

\section{Conclusiones}

1. Una de cada cuatro familias salvadoreñas ha sido víctima de la delincuencia común en el lapso de cuatto meses calendario. Los delitos son cometidos más comúnmente en las zonas urbanas del país, especialmente en el Área Metropolitana de San Salvador, y los afectados con más frecuencia son las personas que viven en los barrios obreros y marginales de las ciudades. Entre los delitos de índole violenta, los que afectan a la población más frecuentemente son el robo a mano armada, la extorsión y las amenazas a muerte; aunque otros delitos más graves como el asesinato y secuestro reportan - comparativamente - bajos porcentajes, la magnitud de los mismos es grave.

2. El seguimiento de los datos de victimización desde 1993 sugiere que el problema de la delincuencia común que afecta al ciudadano promedio, no ha aumentado en los últimos dos años; antes bien, los datos de las encuestas del IUDOP parecen señalar una disminución de los reportes de victimización en el lapso de cuatro meses. Esto no significa que la expresión de la delincuencia sea distinta en la actualidad y que el tipo de delitos cometidos no sea el mismo que en el pasado.
3. La mayor parte de los salvadoreños que han sido víctimas de la violencia delincuencial no avisan a las autoridades del hecho. Esto es especialmente cierto en el caso de los delitos violentos de menor gravedad, pero aún en los hechos más severos quedan importantes porcentajes de población que se resiste a denunciar. Las razones más frecuentes para no hacerlo tienen que ver con la falta de confianza de que las autoridades esclarezcan el delito. De hecho, según los encuestados que sí denunciaron el delito, más de la mitad de las notificaciones a las autoridades no han sido investigadas o resueltas satisfactoriamente para los denunciantes.

4. La Policía Nacional Civil y la Procuraduría para la Defensa de los Derechos Humanos constituyen las instituciones nacionales mejor evaluadas por la lucha en contra del crimen. Las instituciones peor evaluadas por el otro lado son los tribunales de justicia y la presidencia de la república. Las valoraciones sobre el trabajo de las instituciones parecen depender de las experiencias relacionadas con la delincuencia: las personas que no han sufrido por la problemática tienden a evaluar mejor a las instituciones que aquéllas que han sido victimizadas por hechos violentos.

5. La mayor parte de la población está convencida de que el problema de la delincuencia ha aumentado y que sigue en ascenso. Más aún, la tercera parte de la población vive muy angustiada por la problemática. La investigación mostró que en la medida en que la gente se siente más insegura y preocupada por el fenómeno, en esa medida tienden a apoyar medidas más drásticas de represión. Algunas de estas medidas, respaldadas por más de la tercera parte de la población, incluyen el "derecho" a tomarse la justicia por su propia mano, el apoyo a grupos de limpieza social y la adquisición de armamento como forma de protegerse contra la posibilidad de sufrir un delito.

El sondeo del IUDOP sugiere en el fondo que las tendencias de incidencia de los hechos delincuenciales y la preocupación por el fenómeno del crimen no se mueven de la misma forma. No hay evidencias claras de que ahora haya cuantitativamente más delincuencia de la que había en 1993 y 1994; sin embargo, en la actualidad, la gente está mucho más preocupada por el problema que en esos años. A la base de esto se encuentra un fenómeno de acumulación de experiencias y vivencias que no parecen tener un alto radical en el futuro 
próximo, se encuentra también un tratamiento más emocional de las informaciones y una visión más alarmista por parte de algunos medios de comunicación que impacta decididamente en el público y, finalmente, una percepción de que el problema no ha sido solucionado por la ineficacia de las leyes y la falta de capacidad de las autoridades nacionales.

\section{Referencias bibliográficas}

Cruz, J. M. y González, L. A., "Magnitud de la violencia en El Salvador", Estudios Centroamericanos (ECA), 588, 1997, pp. 953-966.

Cruz, J.M., "Los factores posibilitadores y las expresiones de la violencia en los noventa", Estudios Centroamericanos (ECA), 588, 1997, pp. 977-992.

Cruz, J.M., "El papel de la prensa y la opinión pública", Estudios Centroamericanos (ECA), 573-574, 1996, pp. 616-630.

Dirección General de Estadisticas y Censos (DIGESTYC) el al., Proyección de la población de El Salvador, 1995-2000, San Salvador: Ministerio de Economía.

Dirección de Información, Encuesta de hogares de propósitos múltiples 1996, San Salvador: Ministerio de Economía. 1997.
IDHUCA, Los derechos humanos en El Salvador 1996, San Salvador: Instituto de Derechos Humanos de la Universidad Centroamericana "José Simeón Cañas", 1997.

Instituto Universitario de Opinión Pública (IUDOP), Encuesta de opinión sobre delincuencia, Serie de informes 70, San Salvador: IUDOP-UCA, 1998.

Instituto Universitario de Opinión Pública (IUDOP), Encuesta sobre la ley de emergencia y opiniones sobre la delincuencia, Serie de informes 54, San Salvador: IUDOP-UCA, 1996a.

IUDOP. "La violencia en El Salvador", Estudios Centroamericanos (ECA), 569, 1996b, pp. 240-249.

Instituto Universitario de Opinión Pública (IUDOP), "Sistema de justicia, delincuencia corrupción. La opinión de los salvadoreños", Estudios Centroamericanos (ECA), 552, 1994, pp. 1057-1068.

Instituto Universitario de Opinión Pública (IUDOP), "La delincuencia urbana. Encuesta exploratoria" [Documento especial], Estudios Centroamericanos (ECA), 534-535, 1993, pp. 471-479.

Portillo, N. (en prensa). Armas de fuego: ¿una respuesta a la inseguridad ciudadana? Su impacto y prevalencia en el AMSS, Realidad.

Yunes, J. Y Rajs, D., "Tendencia de la mortalidade por causas violentas en la población general y entre los adolescentes y jóvenes de la regiao de las Américas. Cadernos de Saúde Pública, 10, 1994, 88-125. 